\title{
INTRODUCCIÓN A LA TEORÍA DE LOS CUIDADOS CULTURALES ENFERMEROS, DE LA DIVERSIDAD Y LA UNIVERSALIDAD DE MADELEINE LEININGER II (GRÁFICO EXPLICATIVO DEL MODELO DEL SOL NACIENTE DE LEININGER).
}

\section{CECILIA ROHRBACH}

Enfermera antropóloga, Doctorado en sociología y en antropología de la Universidad de Lausanne, Suiza.Docencia e investigación en instituciones interesadas en la ciencia de los cuidados y la cultura. Chemin de Mâcheret 25, 1095 Lutry.

A continuación se reproduce el gráfico del "Modelo del sol naciente" de Leininger representando la teoría de los cuidados culturales de la diversidad y de la universalidad que se corresponde con el artículo aparecido en el número 3 de "Cultura de los Cuidados" con el mismo título que encabeza esta página y del que es autora Cecilia Rohrbach. El mencionado gráfico debe contemplarse a la luz de los datos aportados por el artículo incluido en el número anterior de esta revista.

Modelo del sol naciente de Leininger representando la teoría de los cuidados culturales de la diversidad $y$ de la universalidad

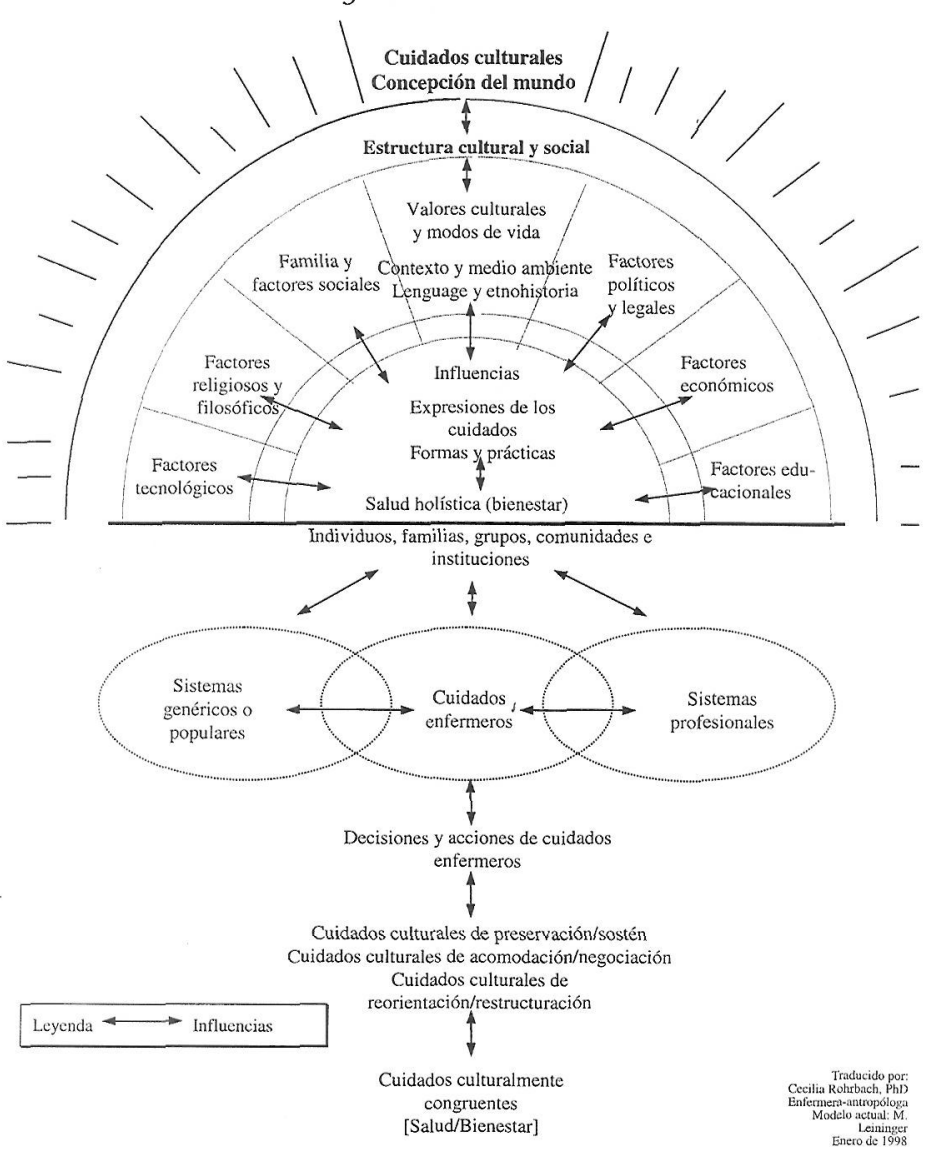

